http://jmscr.igmpublication.org/home/ ISSN (e)-2347-176x ISSN (p) 2455-0450 crossref DOI: https://dx.doi.org/10.18535/jmscr/v7i8.84

$\underline{\text { Research Article }}$

\title{
An Exploratory Study to Assess the Knowledge and Attitude Regarding HIV/AIDS among OPD Patients in Selected Hospitals, Ludhiana, Punjab
}

\author{
Authors \\ Mrs. Manvirpal Kaur ${ }^{1}$, Mrs. Maninder Kaur ${ }^{2}$ \\ ${ }^{1}$ Associate Professor, Medical Surgical Nursing, (Neuroscience in Nursing), GHG College of Nursing, \\ Raikot, Ludhiana, Punjab \\ ${ }^{2}$ Student (2015-2017 Batch), Medical Surgical Nursing, (Cardiovascular and thoracic science in nursing), \\ GHG College of Nursing, Raikot, Ludhiana, Punjab
}

\begin{abstract}
The present study was conducted to assess the knowledge and attitude regarding HIV/AIDS among OPD patients in selected hospitals Ludhiana, Punjab. The conceptual framework of the study was based on, Health Belief Model" of Rosenstoch"s and Mainman"s (1974). A non-experimental research approach and exploratory research design was adopted by using 100 OPD patients were selected by using non probability convenient sampling technique. The purpose of the study is to enhance the knowledge and attitude of OPD patients regarding HIV/AIDS by providing pamphlets. Independent variables in the study were age(in years), gender, type of family, educational status, occupational status, monthly family income, place of living, religion and source of information. The dependent variables in the study were knowledge and attitude regarding HIV/AIDS among OPD patients. A self structured knowledge questionnaire and five-point likert scale was prepared to assess the knowledge and attitude regarding HIV/AIDS among OPD patients. The data was analyzed by using descriptive and inferential statistics. Bar diagrams were used to depict the findings.

Following results were drawn based on the findings of the study. Maximum $40 \%$ of OPD patients belong to age group $\leq 30$ years and were females. Most of the OPD patients $70 \%$ were from nuclear family and 38\% had attained education up to 11th -12th standard. Maximum of the OPD patients 29\% had occupation in private sector and had monthly family income of $\geq 20001$. Most of the OPD patients $73 \%$ belong to Sikh religion and $62 \%$ lived in rural area and maximum $51 \%$ got information through electronic media. The study findings shows that 75(75\%) respondents had good level of knowledge, followed by 17(17\%) had average knowledge and 8(8\%) had excellent knowledge regarding HIV/AIDS. Age, educational status, source of information had relationship with knowledge of respondents significant at $p<0.05$ level. Maximum had $73(73 \%)$ positive attitude. Age and religion had significant relationship with the attitude regarding HIV/AIDS at $p<0.05$ level. There was positive relationship $r=0.575$ between knowledge and attitude on the basis of research findings. Pamphlets were given to create awareness regarding HIV/AIDS among OPD patients.
\end{abstract}

\section{Major Finding}

\section{Demographic Variables}

Maximum percentage of OPD patients 38\% belonged to age group $\leq 30$ years and minimum $9 \%$ were in age group $\geq 51$ years as followed by maximum $56 \%$ were females and remaining $44 \%$ were males. Highest $70 \%$ OPD patients were from nuclear family and lowest $44 \%$ were from 
extended family. Most of the OPD patients $38 \%$ had attained education up to 11-12th standard and lowest $16 \%$ OPD patients had attained education up to graduation and above. Maximum OPD patients $29 \%$ were on private service and minimum $8 \%$ were labourer. Highest $50 \%$ of OPD patients had family monthly income of $\geq 20,000$ and lowest $20 \%$ had family monthly income of Rs. 10,000 to 20,000 . Maximum $73 \%$ OPD patients belong to Sikh religion and minimum $5 \%$ were Christian.

Majority of the OPD patients $51 \%$ got information from electronic media and 10\% of OPD patients got information from health personnel.

\section{Section-B}

Finding related to objective 1- To assess the knowledge regarding HIV/AIDS among OPD patients

- Out of 100 OPD patients majority of $75(75 \%)$ OPD patients had good level of knowledge, only $8(8 \%)$ OPD patients had excellent level of knowledge, 17(17\%) OPD patients had good level of knowledge and no OPD patients had poor level of knowledge regarding HIV/AIDS.

Area wise distribution of mean, mean percentage knowledge score regarding HIV/AIDS among OPD patients.

The total mean percentage of OPD patients had highest mean percentage knowledge score $61.75 \%$ was found in the area of prevention were ranked as 1 , followed by in the introduction $56.25 \%$ were ranked as $2,51.72 \%$ in the area of risk factors were ranked as 3, area of diagnostic evaluation and complication $43.85 \%$ were ranked as $4,42.05 \%$ in the area of signs and symptoms were ranked as 5 and the lowest knowledge score $33.33 \%$ was found in the area of treatment were ranked as 6 .

Hence, it indicates that OPD patients had good knowledge in most of areas while they had less knowledge in the area of treatment regarding HIV/AIDS.

Objective-2 To assess the attitude of OPD patients regarding HIV/AIDS
- Majority of the OPD patients $73(73 \%)$ had positive attitude score and $27(27 \%)$ had negative attitude score regarding HIV/AIDS.

Objective-3 To find out the relationship between knowledge and attitude regarding HIV/AIDS among OPD patients.

There was positive relationship (0.575) between knowledge and attitude regarding HIV/AIDS among OPD patients.

\section{Section-C}

Objective-4 To find out the relationship between knowledge regarding HIV/AIDS among OPD patients with selected demographic variables i.e. age (in years), gender, type of family, educational status, occupational status, monthly family income, religion, place of living and source of information. According to age, maximum mean knowledge score 17.21 was obtained by OPD patients in the age group of $\square 30$ years and the minimum 12.22 was obtained by age group $\geq 51$ years. The relationship of mean knowledge score regarding HIV/AIDS among OPD patients with age was found statistically significant at $\mathrm{p}<0.01$ level.

In relation to gender, maximum mean knowledge score 17.91 of OPD patients were obtained by females and minimum 17.84 obtained by males. The relationship of mean knowledge score regarding HIV/AIDS among OPD patients with gender was found statistically non significant at $\mathrm{p}<0.05$ level.

According to type of family, highest mean knowledge score 18.04 obtained by OPD patients who belonged to joint family and lowest 15.75 from extended family. The relationship of mean knowledge score regarding HIV/AIDS among OPD patients with type of family was found statistically non significant at $p<0.05$ level.

According to educational status, maximum mean knowledge score 21.00 had obtained by those OPD patients who attained education up to graduation where as minimum 15.37 was in 1 st to 5 th standard. The relationship of mean knowledge score regarding HIV/AIDS among OPD patients with educational status was found statistically 
significant at $\mathrm{p}<0.05$ level.

According to occupational status, highest mean knowledge score 18.52 were obtained by those OPD patients who were on private service and lowest mean knowledge score 17.52 was obtained by self employed. The relationship of mean knowledge score regarding HIV/AIDS among OPD patients with occupational status was found statistically non significant at $\mathrm{p}<0.05$ level.

As per monthly family income, highest mean knowledge score 18.53 was obtained by those OPD patients whose had family income ranges between Rs 5001-10,000 and lowest 17.48 from $\geq 20,000$. The relationship of mean knowledge score regarding HIV/AIDS among OPD patients with family monthly income was found statistically non significant at $\mathrm{p}<0.05$ level.

According to religion, highest mean knowledge score 17.95 obtained by those OPD patients who belonged to Sikh religion and minimum mean knowledge score 17.68 were from Hindu religion. The relationship of mean knowledge score regarding HIV/AIDS among OPD patients with religion was found statistically non significant at $\mathrm{p}<0.05$ level.

As per place of living, maximum mean knowledge score 17.90 were obtained by those OPD patients who belong to rural area and minimum mean knowledge score 17.84 was obtained by urban area. The relationship of mean knowledge score regarding HIV/AIDS among OPD patients with place of living was found statistically non significant at $\mathrm{p}<0.05$ level.

According to source of information, maximum mean knowledge score 19.05 had got information from friends/relative and minimum 16.33 from printed media. The relationship of mean knowledge score regarding HIV/AIDS among OPD patients with source of information was found statistically significant at $\mathrm{p}<0.05$ level.

The fifth objective was to find out the relationship of attitude regarding HIV/AIDS among OPD patients with selected demographic variables i.e. age (in years), gender, type of family, educational status, occupational status, monthly family income, religion, place of living and source of information.:-

According to age (in years), maximum mean attitude score 61.67 was obtained by OPD patients in the age group of 41-50 years and the minimum 51.44 was obtained by age group $\geq 51$ years. The relationship of mean attitude score regarding HIV/AIDS among OPD patients with age was found statistically significant at $p<0.05$ level.

In relation to gender, maximum mean attitude score 64.18 of OPD patients were observed by females and minimum obtained by males. The relationship of mean attitude score regarding HIV/AIDS among OPD patients with gender was found statistically non significant at $\mathrm{p}<0.05$ level.

According to type of family, highest mean attitude score 64.37 was obtained by OPD patients who belonged to joint family and lowest $\mathbf{5 7 . 7 5}$ from extended family. The relationship of mean attitude score regarding HIV/AIDS among OPD patients with type of family was found statistically non significant at $\mathrm{p}<0.05$ level.

According to educational status, maximum mean attitude score 65.70 was obtained by those OPD patients who attained education up to graduation and above and minimum 60.61 was obtained by those patients who had attained education up to 6 th to 10th standard. The relationship of mean attitude score regarding HIV/AIDS among OPD patients with educational status was found statistically non significant at $\mathrm{p}<0.05$ level.

According to occupational status, highest mean attitude score 66.75 was obtained by those OPD patients who are labourer and lowest 62.00 of OPD patients were on government service. The relationship of mean attitude score regarding HIV/AIDS among OPD patients with occupational status was found statistically non significant at $\mathrm{p}<0.05$ level.

According to monthly family income, highest mean attitude score 66.00 was obtained by those OPD patients whose monthly family income ranges between Rs.10,001-20,000 and lowest 62.92 from $\geq 20,000$. The relationship of mean attitude score regarding HIV/AIDS among OPD 
patients with monthly family income was found statistically non significant at $\mathrm{p}<0.05$ level.

According to religion, highest mean attitude score 65.40 obtained by those OPD patients who belong to Christian religion, lowest 59.82 were from Hindu religion. The relationship of mean attitude score regarding HIV/AIDS among OPD patients with religion was found statistically significant at $\mathrm{p}<0.05$ level.

As per place of living, maximum mean attitude score 64.77 were obtained by those patients who belong to rural area and minimum 61.89 was obtained by urban area. The relationship of mean attitude score regarding HIV/AIDS among OPD patients with place of living was found statistically non significant at $\mathrm{p}<0.05$ level.

Finding related with source of information of the patients, maximum mean attitude score 65.76 had got information from friends/relatives and minimum 60.61 got information from printed media. The relationship of mean attitude score regarding HIV/AIDS among OPD patients with source of information was found statistically nonsignificant at $\mathrm{p}<0.05$ level

Table-1 Relationship between mean knowledge score regarding HIV/AIDS among OPD patients with educational status.

\begin{tabular}{|c|c|c|c|}
\hline \multirow[b]{3}{*}{ Educational status } & & & $\mathrm{N}=100$ \\
\hline & \multicolumn{3}{|c|}{ Knowledge score } \\
\hline & $\mathrm{n}$ & mean & $\mathrm{SD}$ \\
\hline $1-5^{\text {th }}$ & 19 & 15.37 & 3.201 \\
\hline $6^{\text {th }}$ to $10^{\text {th }}$ & 27 & 16.58 & 2.824 \\
\hline $11^{\text {th }}$ to $12^{\text {th }}$ & 38 & 17.29 & 2.808 \\
\hline Graduation \& above & 16 & 21.00 & 3.033 \\
\hline & $\overline{d f}$ & $\mathrm{~F}$ & \\
\hline Within the group & 96 & $11.464^{*}$ & \\
\hline Between the group & 3 & & \\
\hline
\end{tabular}

Table-2 Relationship of mean knowledge score regarding HIV/AIDS among OPD patients with source of information

\begin{tabular}{|c|c|c|c|}
\hline & & \multicolumn{2}{|c|}{$\mathrm{N}=100$} \\
\hline & & \multicolumn{2}{|c|}{ Knowledge score } \\
\hline Source of information & $\mathbf{n}$ & Mean & SD \\
\hline Printed material & 51 & 17.21 & 2.42 \\
\hline Electronic media & 18 & 16.33 & 2.52 \\
\hline Friends/relatives & 21 & 19.05 & 2.20 \\
\hline Health personal & 10 & 17.90 & 2.18 \\
\hline & df & $\mathbf{F}$ & \\
\hline Between group & 96 & $4.25 * *$ & \\
\hline Within group & 3 & & \\
\hline
\end{tabular}

\section{References}

1. Park K. A Preventive and social medicine. 18th edition. New Delhi: Banarsidas Bhanot; 2010: 19-24.

2. Sepkowitz KA. AIDS- the first 20 years. New England Journal of Medicine. 2010 ; 344 (23): 64-72.
3. Aberg JA, Hoy JF, Thompson MA. Antiretroviral treatment of adult HIV infection JAMA Journal. 2014; 312(4):410-25.

4. United nations programme on HIV and AIDS (2015), UNAIDS fact sheet latest statistics on the status of the AIDS epidemic available at http://unaids.org . 
5. Tondon A, Adult HIV count up in Punjab, Chandigarh; dips across India article on The Tribune available from http://www.tribuneindia.com on 2/12/2015.

6. Godbole S. HIV/AIDS epidemic in India: risk factors, risk behaviour and strategies for prevention and control. Indian Journal Of medical research. 2009;126 (6) : 300 15.

7. Singh M. 2012 Human Immunodeficiency Virus (HIV) available from http://www.manbironline.com/std/hiv.1.htm.

8. Karmacharya D, Yu D, Dixit S, Rajbhandari R, Subrdi B, Shrestha S (2012), UNAIDS fact sheet of the AIDS epidemic available from http://unaids.org

9. Siryana R, 2010 HIV/AIDS transmission available from http://www.mayoclinic.org

10. UNICEF /UNAIDS children and AIDS current status and progress: 2015 available from

https://data.unicef.org/topic/hiv/aids/global -regional-trends.

11. Mandal A 2014, San Francisco AIDS foundation, transmission of HIV/AIDS available from http://sfaf.org/hiv/info/basics/how-is-hivtransfered.html\#

12. Martin H. Prevention of HIV- infection with early antiretroviral therapy. National Engl J Med.2011;365:493-05.

13. Grijsen M. No treatment verses 24 or 60 weeks of antiretroviral therapy during primary HIV infection. PLOS med. 2012; 9(3):110-20.

14. Smallwood M, Pantpai N. Improving the quality of diagnostic studies; problems and recommendation. Journal diagnostics.2016; (7): 5-20. 